\title{
In the era of flexible ureteroscopy is there still a place for Shock-wave lithotripsy?
}

\section{Opinion: NO}

\author{
Fabio C. Vicentini ${ }^{1,2}$ \\ ${ }^{1}$ Endourology and Lithiasis Section, Division of Urology, Hospital das Clinicas, University of São Paulo, \\ School of Medicine, São Paulo, Brazil and ${ }^{2}$ Section of Endourology, Department of Urology, Hospital \\ Brigadeiro, São Paulo, Brazil
}

Keywords: Kidney Calculi; Lithotripsy; Ureteroscopy

Flexible ureteroscopy will replace almost completely ESWL for the treatment of renal stones in few years, even in developing countries. This process is already ongoing and probably is irreversible. Let's try to understand how and why this phenomenon is happening.

Since the development of the External Shockwave Lithotripsy (ESWL) in the late 70's (1), it has been the standard treatment for small renal stones (2). However, recent years have seen a significant shift towards endoscopic therapies (3). This can be attributed to the evolving surgical experience in the use of these techniques, but even more to major improvement in the technical equipment. The question of if the flexible ureteroscopy will substitute ESWL as the choice therapy for renal stones is controversial. First of all, they are not totally comparable, since ESWL is a non-invasive method. If ESWL is not an option no more, we lose a noninvasive method of treatment of renal stones. Otherwise, a non-invasive method doesn't means that it is not harmful, because its association with late development of diabetes and hypertension is still controversial, while a link between ESWL and phosphate calcium stones is possible (4). However, as flexible ureteroscopy has higher success rates, it can be justified, since the complications rates are low. Regarding the cost, in some services the flexible ureteroscopy is cost effective compared to ESWL (5).

If we see this issue from a current point of view only, it sounds almost absurd to state that ESWL will disappear. Almost 60\% of renal stones today are treatment by ESWL, at low cost and low complications rates. No one should close an ESWL service that is established and working properly. The urological guidelines support the use of ESWL for renal and ureteral stones $(2,6)$. However, we are discussing the future of renal stones treatment, what includes search for better treatments, with lower costs, higher success rates and low complications rates, with a high acceptance and satisfaction of the patients. 
What we observe worldwide and in Brazil currently is an increase in the use of flexible and a decrease in the $\operatorname{ESWL}(3,7,8)$.

Herein, we describe some reasons for this change that we have observed:

1. Flexible ureteroscopy has been taught for many years in residency programs, congresses and specific courses for that. So, more urologists are able to perform an adequate flexible ureteroscopy.

2. The flexible ureteroscope has suffering tremendous advances and nowadays it is more durable, with small caliber and with improved vision with the digital system. With adequate care, a flexible ureteroscope can last for a hundred procedures or more, what diminishes the total cost of the procedure $(9,10)$.

3. The cost of the flexible ureteroscopy has decreasing and is much more affordable today than it was a few years ago. Conversely, the cost of a new ESWL machine is still high and we do not observe a decrease in prices with the new equipment and there is considerable maintenance cost $(11,12)$.

4. The new ESWL machines fails in demonstrate better results than the old models. None modern ESWL equipment showed to be better than the Dornier HM-3, the first equipment developed (13).

5. New disposables devices have been introduced almost daily, as ureteral sheaths, baskets, laser fibers, what can improve the outcomes (14).

6. There is an undeniable commercial and marketing appeal on flexible, a fact that is less observed with the ESWL machines.

7. Residents and young urologists prefer to do a flexible rather than an ESWL (15).

8. Reimbursement for flexible ureteroscopy is usually higher than for ESWL.

9. Outcomes of flexible ureteroscopy are superior than ESWL in a single session (6).

Normally, ESWL equipment occupies a considerable physical space in the hospital, many times inside a surgical center, with a post-operative room for the patients. That room is expensive, because usually it is underused during the day and stays closed during the night and weekends. It could have others use, more rentable for the Hospital.

Movable lithotripsy services were proposed in the North America and Europe in order to solve this problem. A truck was built with an ESWL machine inside and went to the hospitals to treat the patients. Nevertheless, the success rates published recently are about 50\% (16). These poor results can compromise seriously the life of these mobile ESWL.

If you or your Institution have an ESWL service, keep using it, because you are offering a good and recommended treatment for the patients and the acquisition cost of the machine must be paid. However, in a strict administrative point of view (and administrators that make purchases for the hospitals), who is going to buy a new ESWL machine today, that is expensive, has a considerable maintenance cost, is each time less indicated for the urologists, occupies a relatively big and expensive space in the Hospital, if you can buy 2 or 3 flexibles ureteroscopes that will have a lower total cost for the institution, treat the patients more efficiently and is required by the urologists?

So, ESWL will die?

In my view, will not, and nor should die. But certainly it use will decrease a lot, until stabilize around 10 to $20 \%$ of all stone treatments. One possible solution is to create regional reference centers that will drain the cases of a determined region, with good 
machines (17) and a dedicate team focused in apply all the recommended techniques to improve the outcomes, including a good selection of the patients based on the CT scan analysis (18), performing an adequate procedure, under sedation or general anesthesia, with good gel coupling, with frequency between 60 and $90 \mathrm{~Hz}$ (19), progressive increase of potency, and use of alpha-blockers after the procedure, mainly for stones bigger than $10 \mathrm{~mm}$ (20). This can give an extra life for the ESWL, making justice with one of the most incredible advances of the urology history.

But, as stated in the beginning of this article, flexible ureteroscopy will probably replace almost completely the use of ESWL in the clinical practice in few years, even in developing countries, unless arising another non-invasive technology that is cheaper and with high success rates (21).

\section{REFERENCES}

1. Schmiedt E, Chaussy C. Extracorporeal shockwave lithotripsy (ESWL) of kidney and ureteric stones. Int Urol Nephrol. 1984;16:273-83.

2. Preminger GM, Assimos DG, Lingeman JE, Nakada SY, Pearle MS, Wolf JS Jr; AUA Nephrolithiasis Guideline Panel). Chapter 1: AUA guideline on management of staghorn calculi: diagnosis and treatment recommendations. J Urol. 2005;173:1991-2000.

3. Marchini GS, Mello MF, Levy R, Vicentini FC, Torricelli FC, Eluf-Neto J,et al. Contemporary Trends of Inpatient Surgical Management of Stone Disease: National Analysis in an Economic Growth Scenario. J Endourol. 2015. [Epub ahead of print]

4. Evan AP, Coe FL, Connors BA, Handa RK, Lingeman JE, Worcester EM. Mechanism by which shock wave lithotripsy can promote formation of human calcium phosphate stones. Am J Physiol Renal Physiol. 2015;308:F938-49.

5. Cone EB, Eisner BH, Ursiny M, Pareek G. Costeffectiveness comparison of renal calculi treated with ureteroscopic laser lithotripsy versus shockwave lithotripsy. J Endourol. 2014;28:63943.

6. Turk C, Knoll T, Petrik A, Sarica K, Skolarikos A, Struab M, et al. Guidelines on urolithiasis. Eur Assoc Urol. Available at. http://www.uroweb.org/ guidelines/online-guidelines/2013.

7. Matlaga BR; American Board of Urology. Contemporary surgical management of upper urinary tract calculi. J Urol. 2009;181:2152-6.
8. Seklehner S, Laudano MA, Del Pizzo J, Chughtai $B$, Lee RK. Renal calculi: trends in the utilization of shockwave lithotripsy and ureteroscopy. Can J Urol. 2015;22:7627-34.

9. Multescu R, Geavlete B, Georgescu D, Geavlete P. Improved durability of flex-Xc digital flexible ureteroscope: how long can you expect it to last? Urology. 2014;84:32-5.

10. Defidio L, De Dominicis M, Di Gianfrancesco L, Fuchs G, Patel A. Improving flexible ureterorenoscope durability up to 100 procedures. J Endourol. 2012;26:1329-34.

11. Huang CY, Chen SS, Chen LK. Cost-effectiveness of treating ureteral stones in a Taipei City Hospital: shock wave lithotripsy versus ureteroscopy plus lithoclast. Urol Int. 2009;83:410-5.

12. Gurbuz C, Atı G, Arikan 0, Efilioglu 0, Yıldırım A, Danacioglu 0 , et al. The cost analysis of flexible ureteroscopic lithotripsy in 302 cases. Urolithiasis. 2014;42:155-8.

13. Neisius A, Wöllner J, Thomas C, Roos FC, Brenner W, Hampel C, et al. Treatment efficacy and outcomes using a third generation shockwave lithotripter. BJU Int. 2013;112:972-81.

14. Shin RH, Lipkin ME, Preminger GM. Disposable devices for RIRS: where do we stand in 2013? What do we need in the future? World $\mathrm{J}$ Urol. 2015;33:241-6.

15. Childs MA, Rangel LJ, Lingeman JE, Krambeck AE. Factors influencing urologist treatment preference in surgical management of stone disease. Urology. 2012;79:996-1003.

16. Nafie S, Dyer JE, Minhas JS, Mills JA, Khan MA. Efficacy of a móbile lithotripsy service: a one-year review of 222 patients. Scand J Urol. 2014;48:324-7. 
17. Rassweiler J, Rassweiler MC, Frede T, Alken P. Extracorporeal shock wave lithotripsy: An opinion on its future. Indian J Urol. 2014;30:73-9.

18. Torricelli FC, Marchini GS, Yamauchi FI, Danilovic A, Vicentini FC, Srougi M,et al. Impact of Renal Anatomy on Shock Wave Lithotripsy Outcomes for Lower Pole Kidney Stones: Results of a Prospective Multifactorial Analysis Controlled by Computerized Tomography. J Urol. 2014. [Epub ahead of print]

19. Mazzucchi E, Brito AH, Danilovic A, Ebaid GX, Chedid Neto E, Azevedo JR,et al. Comparison between two shock wave regimens using frequencies of 60 and 90 impulses per minute for urinary stones. Clinics (Sao Paulo). 2010;65:961-5.
20. Vicentini FC, Mazzucchi E, Brito AH, Chedid Neto EA, Danilovic A, Srougi M. Adjuvant tamsulosin or nifedipine after extracorporeal shock wave lithotripsy for renal stones: a double blind, randomized, placebocontrolled trial. Urology. 2011;78:1016-21.

21. Maxwell AD, Cunitz BW, Kreider W, Sapozhnikov OA, Hsi RS, Harper JD, et al. Fragmentation of urinary calculi in vitro by burst wave lithotripsy. J Urol. 2015;193:338-44.

Fabio C. Vicentini, $M D, P h D$ Department of Urology, Hospital das Clínicas de São Paulo Av. Enéas de Carvalho Aguiar, 255 São Paulo, SP, 05403-000, Brazil Telephone: +55 11 2661-8080 E-mail:fabio@drfabiovicentini.com.br 